\title{
Life Cycle Costs of Dutch school buildings
}

\author{
C-8: Green buildings \& Environmental policies, Saturday 6-7-2013, 9:00-10:30, \#140
}

Peter de Jong (corresponding author p.dejong@tudelft.nl) \& Monique Arkesteijn, Real Estate \& Housing, Faculty of Architecture and The Built Environment, Delft University of Technology, Delft, The Netherlands

\section{Abstract}

There is a gap between investment and operating costs of public school buildings in the Netherlands. This gap is caused by separated responsibility for the financing of the accommodation for the primary and secondary schools. Municipalities finance the initial costs of construction of these schools and school boards are responsible for the operating costs of the school building. According to architecture-based research on this subject (In 't Veld, Hamdan, \& Barendregt, 2010) this split-up results in higher costs during the lifetime. This problem is often referred to as the split-incentive problem. The purpose of this article is to add case based evidence in order to support the idea that an integral approach captured in life cycle costs (LCC) will lead to more in-depth argued adjustments of school buildings.

The research conducted nine case studies of secondary school buildings, which are newly build between 2005 and 2008. The schools were examined in terms of buildings characteristics, building costs and operations costs. With the aid of the Dutch sustainability measurement tool GPR-Gebouw ${ }^{1}$ the sustainability score of the schools is determined.

For the construction sector in the Netherlands it can be concluded that it is generally acknowledged that sustainability is more expensive, however, studies indicate this is not unequivocally. An elaborated research of Davis Langdon reveals within a given spread of building costs an equal spread of certified buildings (Morris \& Matthiessen, 2007). Our study supports this finding and found at least no clear relationship that sustainable schools have higher investment costs. The study shows a positive effect of sustainable measurements on the life cycle costs of secondary schools.

There is an on-going discussion on ratios between initial costs and operating costs. Evans (1998) stated that there is a ratio of 1:5:200 between the construction costs, operating expenses and corporate operating costs. This ratio has already been further defined and reduced by Hughes (2004) and Ive (2007). The scenario analysis of our study shows that the operating costs still have a larger share in the life cycle costs than the investment costs. The difference between the investment and operating according to this study is by far not as impressive as stated by Evans, but still worthwhile to keep focus on LCC in policies for school development.

Keywords: Life cycle costs, school buildings, sustainability

\section{Introduction}

Many schools in the Netherlands have inadequate housing. Buildings are old ${ }^{2}$ and poorly maintained and in addition to that most schools have a poor climate (Van der Pol, 2009). Also the buildings do not conform to contemporary demands for quality education (De Jong, 2011; In 't Veld et al., 2010).

In 1997 the responsibility and budget for accommodation for schools for primary, special and secondary education is decentralized from central government to the municipalities. Since financing for school buildings is divided in two budgets, one for the initial costs of new buildings, governed by the municipality and one for maintenance and operation, run by the school board. Although, both institutions can add additional funds, both cash flows basically come from the same national government, one by the Home office through a fund for the municipalities and the other by the Ministry of Education by lump sum financing.

Sustainable projects are based upon an integrated approach (Van Doorn \& De Jong, 2012). It is strongly suggested separation in funding does not lead to sustainable solutions, even if municipalities as well as school

\footnotetext{
${ }^{1}$ GPR Building http://gprsoftware.nl/english/sustainability-assessment/gpr-building/

${ }^{2}$ For a recent case study research for the 'scholenbouwatlas' the average age of a representative selection of 70 schools for primary education and day-care in the Netherlands was 67 years.
} 
boards are trying hard. The idea that low investment budget will results in cost overrun of the lifecycle costs is commonly accepted. However, Hughes (2004) already showed the lack of proper data on operating costs. So there is a need to gather data in order to quantify such a judgements.

It is also difficult to determine the compound cost overrun where the budget is focussing on the initial approach, resulting in an as-is approach for the operation budget. In an ideal situation one should be able to compare initial and operating costs in a life cycle costs model of schools within and outside the system in order to come to an evidence-based conclusion. A first step towards such a comparison is the analysis of the performance of schools in the given situation.

This analysis is conducted on nine case studies of secondary school buildings which are newly build between 2005 and 2008, within the portfolio of HEVO, a specialised project management organisation ${ }^{3}$ by Jasper van Langen during his graduation (2012) ${ }^{4}$. These schools were examined in terms of buildings characteristics, building costs and operations costs. First the research method is explained and as an example one case, Trinitas College of Johannes Bosco is described. The next element in this paper is the cross-case analysis over the nine cases with detailed conclusions, after which more generic conclusions are drawn and discussed.

\section{Research process}

The main question of this research is: how do newly built school buildings for middle-level applied education $(\mathrm{MBO})^{5}$ perform on life cycle costs?

For homogeneous data collection the cases are selected within this same typology of schools, by its nature dedicated to practical training and classroom learning under similar conditions (official requirements and financial boundaries). For this reason, as well as for logistical reasons all cases are newly build between 2005 and 2008, all connected by to a single real estate consultancy company.

For each case the collected data was:

- general data on the school

- drawings, as supplied for the building permit

- energy calculations (EPC) also as supplied for this permit

- investment calculations, source municipality/governing body of the school

- operating costs for 2 years, source governing body of the school

- energy use

$\circ$ cleaning

- maintenance (preventive) and service

Drawings and energy calculations are used to conduct the GPR Building calculations. Based upon the cost data the LCC-calculations are elaborated on a 40 year base 6 . For comparison between cases all costs are recalculated to costs per $m^{2}$ GFA.

\section{Rationale for the selection of sustainability tools}

The cross case analyses will be directed to the life cycle costs approach, relating costs performance with sustainable performance. Based upon an all-encompassing evaluation (Van Langen, 2012) of several theories on sustainable building, like Trias Energetica (Van den Dobbelsteen, 2008) and Cradle to cradle (McDonough \& Braungart, 2002), the need for flexibility as a sustainable concept (Remøy, de Jong, \& Schenk, 2011) and comparison of measurement tools like BREEAM. $\mathrm{ll}^{7}$, LEED ${ }^{8}$, GreenCalc $+{ }^{9}$ and EVR (De Jonge, 2005), EPC and GPR Building, the last two tools are selected. EPC stands for the Energy Performance Coefficient which includes an in-

\footnotetext{
${ }^{3}$ www.hevo.nl

${ }^{4}$ The student was guided by the authors.

${ }^{5}$ Middle-level applied education takes up to four years. Those who complete their training can start work or go on to another form of education. It prepares students for a wide range of occupations. Holders of a level 4 MBO certificate may go on to higher professional education (HBO).

${ }^{6}$ A debatable choice: the previously mentioned research on primary schools revealed an average age of 67 years, suggesting lifetimes are going towards 80 years. At the same time the cases showed numerous conversions.

${ }^{7}$ www.breeam.nl

${ }^{8}$ www.usgbc.org/leed

${ }^{9}$ www.greencalc.com/
} 
depth calculation method; a calculation in which, based upon standardised consumption the energy demand is elaborated, resulting in a numeral. The Dutch building code has defined the limit for this value per function. In 2011, the EPC for newly built houses was refined from 0.8 to 0.6 . In 2009 the EPC for utility buildings were already sharpened by an average of $20 \%$.

GPR Building is an assessment tool for comparative ranking of the sustainable performance. In the GPR division is made in 5 themes: Energy, Environment, Health, User Quality and Future Value. Being a compulsory standard, the EPC is the main component of the energy theme.

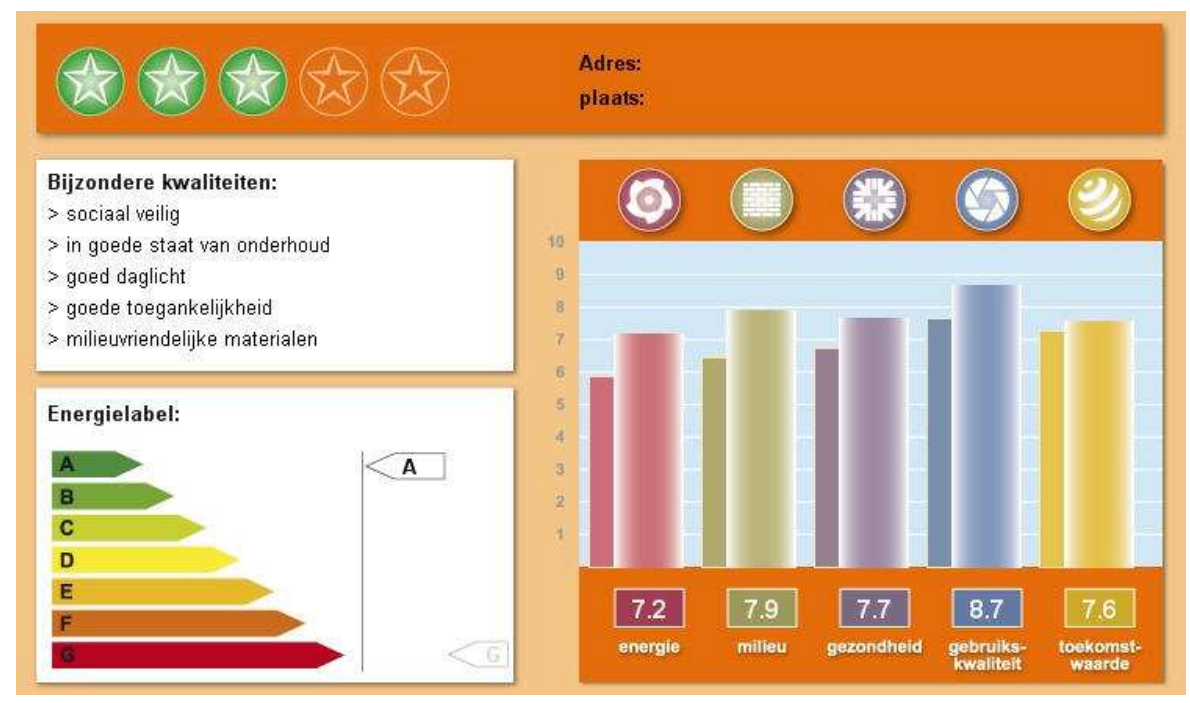

Figure 1 Presentation of GPR results, on the left some remarkable qualities (in this case social secure, proper state of maintenance, good daylight and accessibility and good environmental materials) and the energy label, and on the right the performance on the 5 themes: Energy, Environment, Health, User Quality and Future Value.

The selection of tools is not a disqualification of the other tools evaluated, but the selected tools provide the best match with tools used by the municipality, easing comparison.

\section{Life cycle costs}

The life cycle costs are calculated based on the European standard (NEN-ISO, 2008), see also Figure 2. For this study, the environment costs are not taken into account. An exit value is applied as an alternative. Although environment costs do take a prominent place in the overview of WLC and LCC elements (NEN-ISO, 2008, p. 6), the examples in this standard allow exclusion (NEN-ISO, 2008, p. 7). For an advanced approach including these environment costs other methods such as the EVR could have been used. Without compulsion figures on these environmental costs are not supplied by facility management nor used by commercial partners.

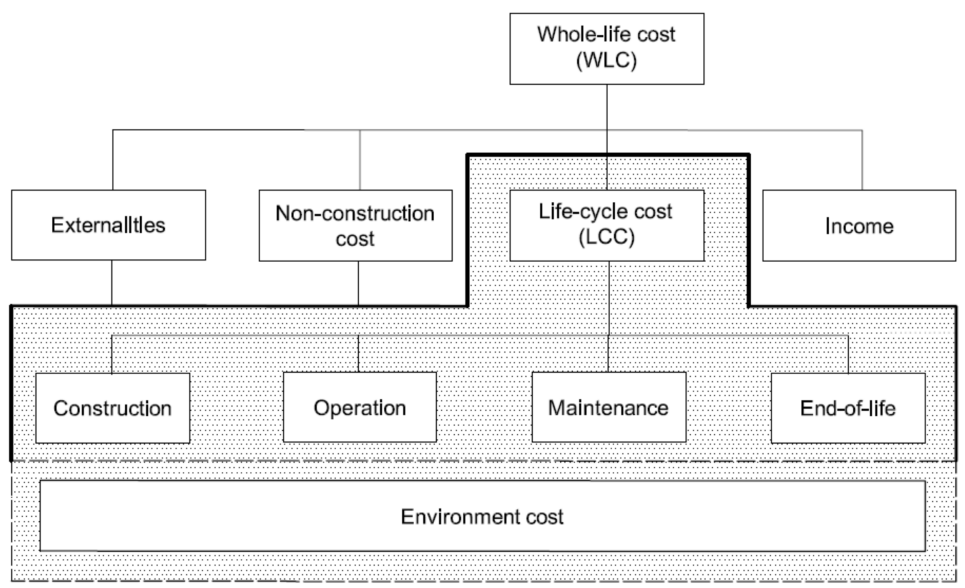

Figure 2 Graphical representation of costs (NEN-ISO, 2008) 
The period of analysis is 40 years, after which a residual value is calculated, assuming that the actual operating costs continue to be the same in the remainder of the lifespan. Such an approach suggests an afterlife following this period of use in the designated function, meaning that the final End-of-life costs for demolition is not considered.

In the life cycle costs calculations the following parameters are applied.

- $\quad$ Standard inflation $2.1 \%$

Although the current inflation (June 2013) is substantially higher, long term inflation tends towards the level of $2.1 \%$.

- $\quad$ Energy inflation $6.8 \%$

Based upon comparison between standard allowance for schools and energy prices over the last decade (2012), but decreasing at the moment.

- Discount rate of $4 \%$

Applied in the calculation of discounted cash flows, selected for similarity with calculations used by the municipality.

- $\quad$ Interest rate $3 \%$

Applied in the calculation of initial costs with the same argument.

The outcome of life cycle costs calculations is strongly influenced by the selection of these figures. To what extent should the current situation be taken into account - it is expected the sharp edges of the crises will flatten out again, so e.g. a more long term average interest rate is used. Energy inflation is decreasing at the moment, but depending on the sources, will stabilise (optimistic scenario/industry) or increase (IEA). The increase could be extensively according to many scientist concerned with depletion of resources.

\section{Case Trinitas College, Johannes Bosco}

The case of the Johannes Bosco is elaborated here as an example being a representative case.

General data

Trinitas College, Building

Johannes Bosco

Location

Heerhugowaard, the Netherlands

Number of students

1200 at Johannes Bosco, of (counted at 2010) total 2300 at Trinitas College

Year completed 2007

Architect

De Jong Gortemaker Algra

Investment costs $€ 14.900 .000$,- ex. VAT

(price index 2012) $€ 1.150 / \mathrm{m}^{2}$ GFA

The building Johannes Bosco belongs to the Trinitas College, together with the Han Fortmann College. Both departments were procured at the same time.

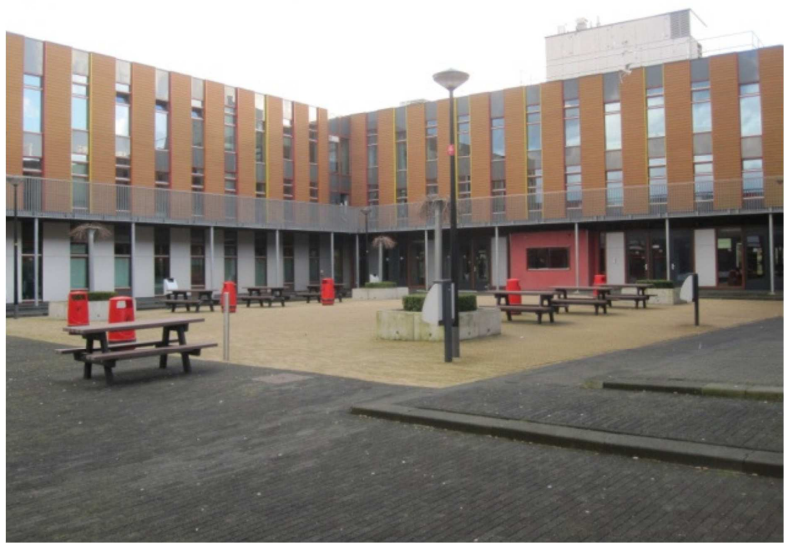

Figure 3 View on courtyard

The Johannes Bosco building contains two building blocks. The upper part houses mainly classrooms. The lower part contains sports centres and rooms for technical education. Both blocks are linked together with a footbridge on the first floor.

Design attributes

Gross floor area (GFA)

Usable area (UA)

Façade

Roof

Traffic area

$\begin{aligned} 12,942 & \mathrm{~m}^{2} \\ 11,867 & \mathrm{~m}^{2} \\ 6,035 & \mathrm{~m}^{2} \\ 5,161 & \mathrm{~m}^{2} \\ 2,594 & \mathrm{~m}^{2}\end{aligned}$

Shape factors (Gerritse, 2007)

Stacking 2.5 -

Compactness 0.47 Façade/GFA

Efficiency $69 \%$ UA/GFA

GFA/student $10.4 \mathrm{~m}^{2}$

Av. room size $47.5 \mathrm{~m}^{2}$

The building blocks are using different installation systems. The 'theory'-block is using heath storage in combination with floor heating. The ceilings are half open with mechanical balance ventilation and heath recovery. The block for practical education is using a standard concept with high efficiency boilers and radiators. The calculated energy label is A. In GPR-scores on energy 7.1, environment 7.4, health 7.7, user quality 8.9 and future value 7.7. 
The Johannes Bosco is a so-called IFD (industrial flexible and demountable) building. There are no bearing inner walls. Due to the grid system the building is very flexible, causing the high score on future value. By integration of networks for audio, video, building control, security, phone and ICT based upon Ethernet with glass fibre and a duct system materials are reduced and fully demountable and recyclable.

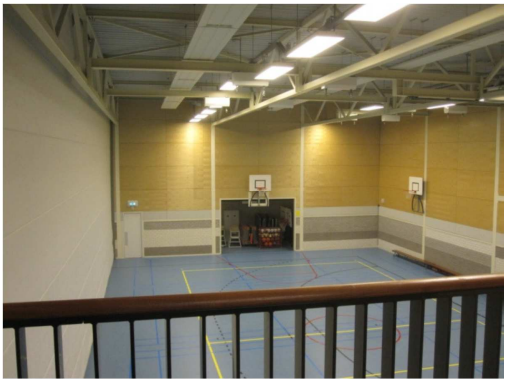

Figure 4 Sport centre

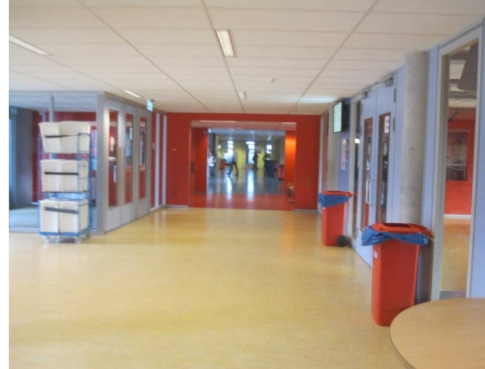

Figure 5 Hallway in theory building

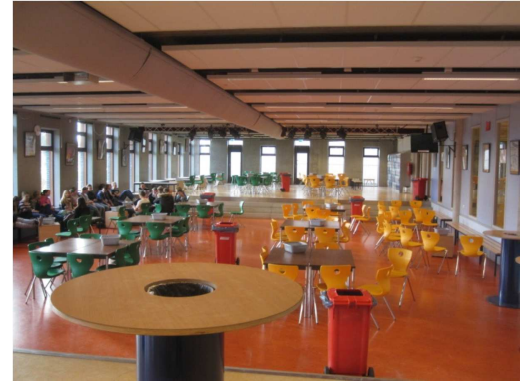

Figure 6 Auditorium

This school has a multiple year maintenance schedule for 40 years used for reservation for replacement.

$\begin{array}{lrrr}\text { Operating costs } & 2009 & 2010 & \text { Average per m } \mathrm{m}^{2} \text { GFA } \\ \text { Energy } & € 102.982 & € 100.357 & € 8,10 \\ \text { Cleaning } & € 156.751 & € 125.522 & € 11,00 \\ \text { Replacement } & € 259.011 & € 282.130 & € 20,90 \\ \text { Maintenance } & € 64.852 & € 74.752 & € 5,40 \\ \text { Total } & € 602.446 & € 514.210 & € 36,00 \\ \text { Table 1 Operating costs Johannes Bosco } & \end{array}$

The calculation of the life cycle costs, using the figures stated before, also depend on the exit value. Most municipalities use an exit value of 0 after 40 years. Although this is rather disputable given the fact that the stock shows a longer actual lifetime, this approach is used for comparison in order to make a cross case analysis. The initial construction costs are treated in an accounting approach, also practised by the municipalities, delivering a net present value of depreciation and interest.

\section{Cross case analysis}

The first result of the cross case analysis is the average compound building related operating costs of $€ 46 / \mathrm{m}^{2}$ GFA. These costs, energy, cleaning and maintenance is $92 \%$ of the total operating costs, resulting in an average of $€ 50 / \mathrm{m}^{2}$ GFA. This building related average is based on the benchmark of HEVO $(\diamond)$ and the cases of Van Langen $(\diamond)$.

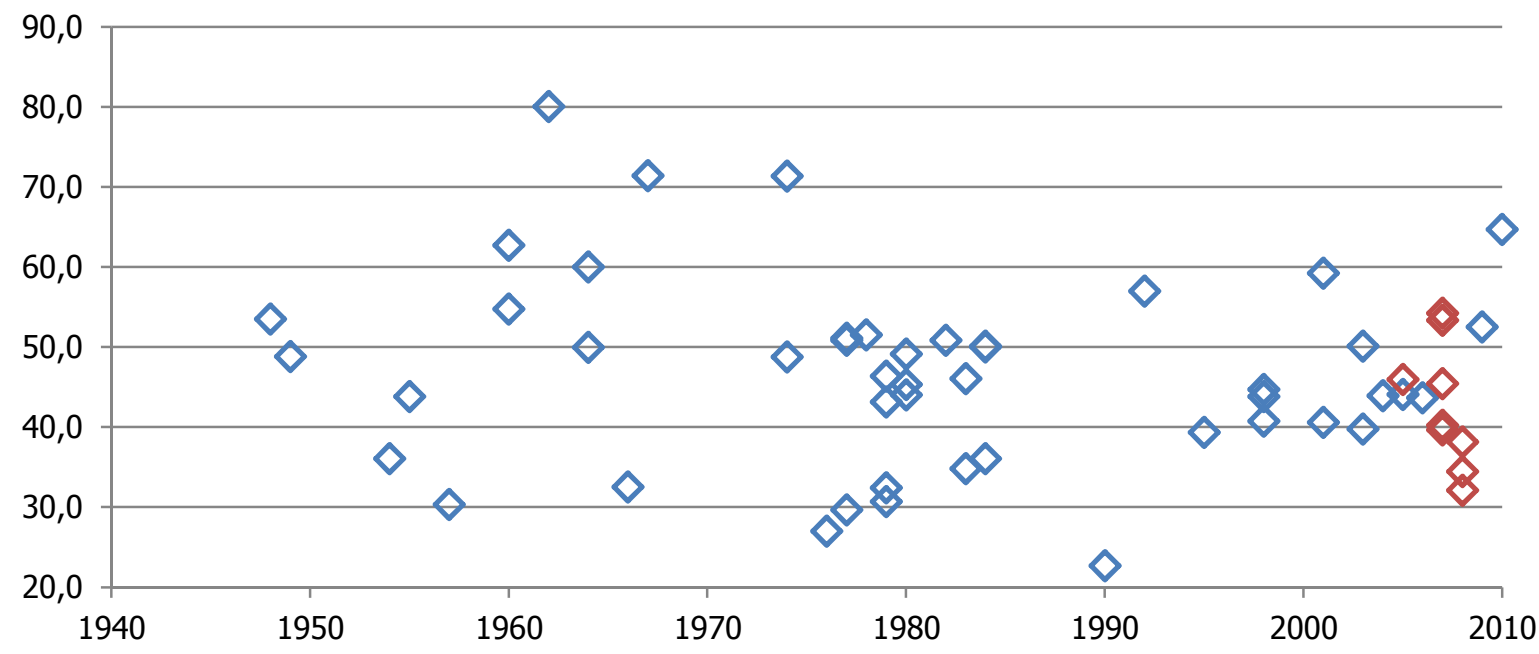


The spread shown in this graph suggest there is still a lot to improve. A more detailed case-based explanation is needed in order to understand why a single school can score almost 4 times higher in operating costs compared to the lowest score (and how they can deal with it). The dataset consists of schools for applied education as well as theoretical education. The operating costs per $\mathrm{m}^{2} \mathrm{GFA}$ of the theoretical education is slightly higher $\left(€ 51 / \mathrm{m}^{2}\right.$ GFA) compared to applied education ( $€ 42-43 / \mathrm{m}^{2} \mathrm{GFA}$ ). This may seem remarkable since applied education would take more maintenance, but the applied education is more voluminous, causing a better score per $\mathrm{m}^{2} \mathrm{GFA}$ : (theoretical education has $9.4 \mathrm{~m}^{2}$ GFA per student and applied education has $13.3 \mathrm{~m}^{2}$.

Hereafter the research is focussing on the 9 cases. The weighted average initial costs of these 9 newly built schools for middle-level applied education is $€ 1340 / \mathrm{m}^{2}$ GFA (price level 2010). A weighted average is used in order to reduce the impact of project size. The cases are roughly following the normal trend in which smaller buildings have higher building costs. The GFA varies from 4742 to $23742 \mathrm{~m}^{2}$ where the building costs varies from 1242 to $1539 € / \mathrm{m}^{2}$ GFA. All cases are analysed on building characteristics like efficiency, shape, stacking and compactness, not resulting in any arguments for excluding cases as outliers. Efficiency varies from $69 \%$ to $79 \%$ (usable floor space/GFA) which is normal in this typology.

As explained previously GPR is used for evaluation of the sustainable characteristics.

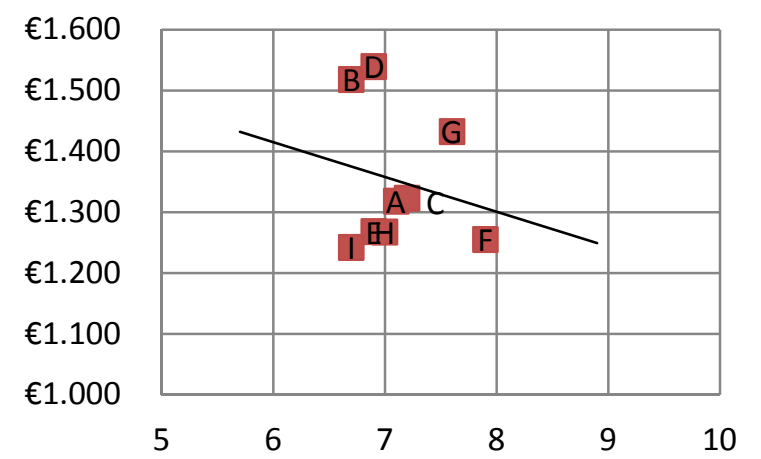

Graph 2 Energy

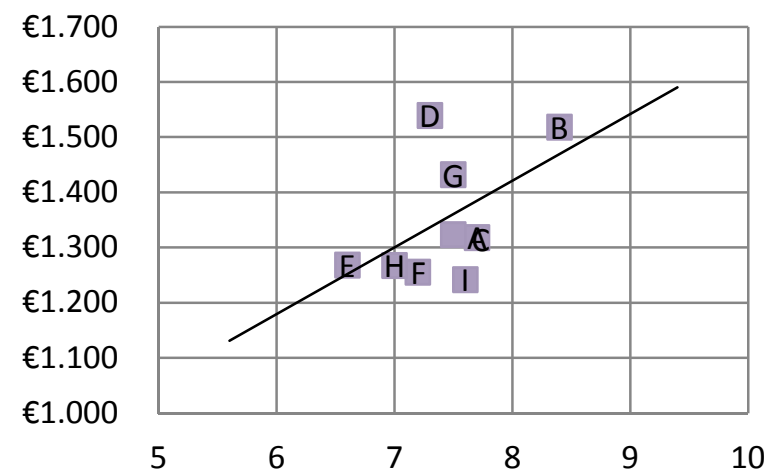

Graph 4 Health

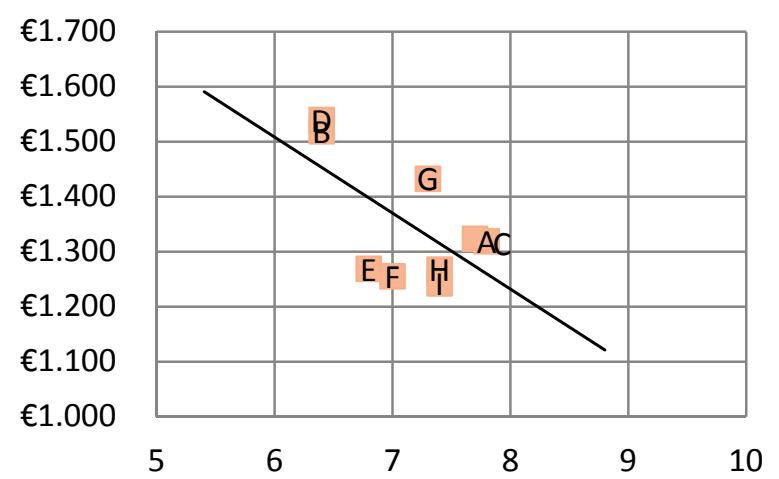

$€ 1.600$

$€ 1.500$

$€ 1.400$

$€ 1.300$

$€ 1.200$

$€ 1.100$

$€ 1.000$

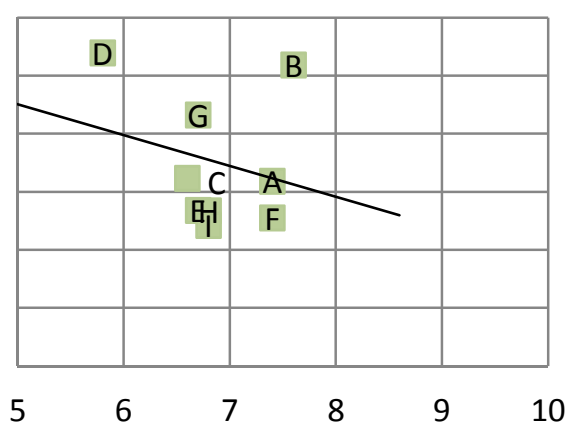

Graph 3 Environment

$€ 1.600$

$€ 1.500$

$€ 1.400$

$€ 1.300$

$€ 1.200$

$€ 1.100$

$€ 1.000$

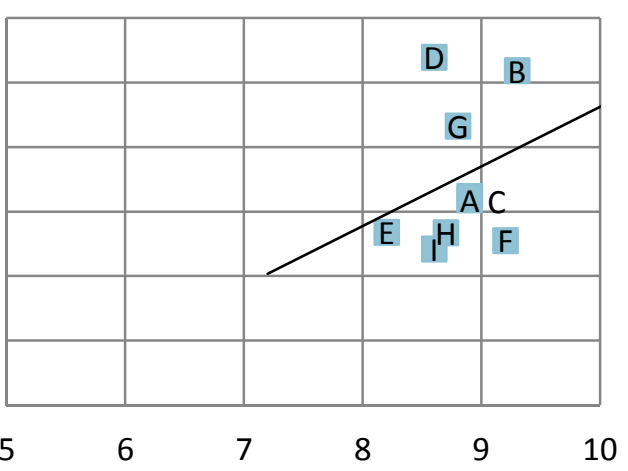

Graph 5 User Quality

The vertical axis shows the initial costs per $\mathrm{m}^{2} \mathrm{GFA}$, on the horizontal axis the GPR-score is given (a higher score is a better performance).

The range in the GPR-score is in most graphs narrow, causing questions with the use of trend lines. However a declining trend line is remarkable, suggesting increased building costs do not lead to improved performance, or at least money spend on other issues. 
Also in comparable graphs in which the EPC, the theoretical performance is related to the actual costs of energy, are showing that those buildings which should be more energy efficient do not reach this expectation in all cases. In the majority of these 9 cases it is the other way around, leading to a negative trend line. During the research it appeared several schools had difficulties with an optimal regulation of their installations.

The best performing schools on energy costs have floor heating and use low temperature of the water for the heating of the building. The bandwidth of the gas / heating costs for buildings with floor heating is between $€$ 1.80 - $€ 5.50$ per square meter GFA and for buildings that are heated by radiators $€ 4.00-€ 8.10$ per square meter GFA. Also the optimum in energy costs can be perceived by buildings with floor heating, low temperature heating possibly in combination with soil storage.

The maintenance costs are responsibility for $16 \%$ of the life cycle costs. These costs are difficult to compare, because the maintenance strategy and the long-term maintenance planning period have a major impact on the actual and accounted costs made for maintenance.

Cleaning costs take a share of $15 \%$ of life cycle costs. The data in this study shows that the outsourcing to a cleaning company saves on cleaning delivery. The bandwidth of the cleaning of schools where the cleaning is performed in-house is between $€ 11.50-€ 22.70$ per square meter GFA and schools where it is outsourced between $€ 8.00$ - $€ 11.00$ per square meter GFA. An optimization of the cleaning costs must therefore be sought mainly in the organization. The materialization of the building also has a limited influence.

\section{Life cycle costs}

In the table below the resulting LCC per case are given. Due to different circumstances there are the LCC varies a lot. E.g. in cases $A, C$ and $H$ cleaning is outsourced, with an average of cleaning at $€ 9.2 / \mathrm{m}^{2}$ GFA while the others take care of cleaning themselves with an average of $€ 16.4 / \mathrm{m}^{2} \mathrm{GFA}$.

$\begin{array}{clr}\text { Case } & \text { Name } & \text { LCC per m } \mathbf{~}^{2} \\ \text { A } & \text { Johannes Bosco } & € 2932 \\ \text { B } & \text { Niekée } & € 3201 \\ \text { C } & \text { Sevenwolden } & € 2915 \\ \text { D } & \text { Connect College } & € 3240 \\ \text { E } & \text { Casparus College } & € 3167 \\ \text { F } & \text { Insula College } & € 3539 \\ \text { G } & \text { Lek en Linge } & € 2719 \\ \text { H } & \text { SG Were Di } & € 2627 \\ \text { I } & \text { Westerpoort College } & € 2822 \\ \text { Table 2 LCC cases (no exit value) } & \end{array}$

Case $\mathrm{H}$, the comprehensive school Were $\mathrm{Di}$ is doing well due to:

$$
\begin{array}{ll}
\text { - } & \text { Low initial costs of } € 1267 \text { per } \mathrm{m}^{2} \text { GFA } \\
\text { - } & \text { Very low cleaning costs of } € 8,50 \text { per } \mathrm{m}^{2} \text { GFA } \\
\text { - } & \text { Average maintenance costs of } € 14,70 \text { per } \mathrm{m}^{2} \text { GFA } \\
\text { - } & \text { Low energy costs of } € 12,10 \text { per } \mathrm{m}^{2} \text { GFA }
\end{array}
$$

Case $F$, the Insula college is not doing well due to:

$$
\begin{array}{ll}
\text { - } & \text { Low initial costs of } € 1255 \text { per } \mathrm{m}^{2} \text { GFA } \\
\text { - } & \text { High cleaning costs of } € 20 \text { per } \mathrm{m}^{2} \text { GFA } \\
\text { - } & \text { Low maintenance costs of } € 11,60 \text { per } \mathrm{m}^{2} \text { GFA } \\
\text { - } & \text { Very high energy costs of } € 22,60 \text { per } \mathrm{m}^{2} \text { GFA }
\end{array}
$$

The good news for this school is the provisional situation. They have had many problems with temperature control, for which even mobile air conditioning units are deployed. It took a long time to regulate all systems.

As stated before, LCC calculations are highly conditional upon the economic parameters, for which different scenarios are applied. The ratio between initial capital costs and operating costs varies in these scenarios from 1.15 to 1.59 with for the standard (or most expected) scenario the result is 1.37 . 


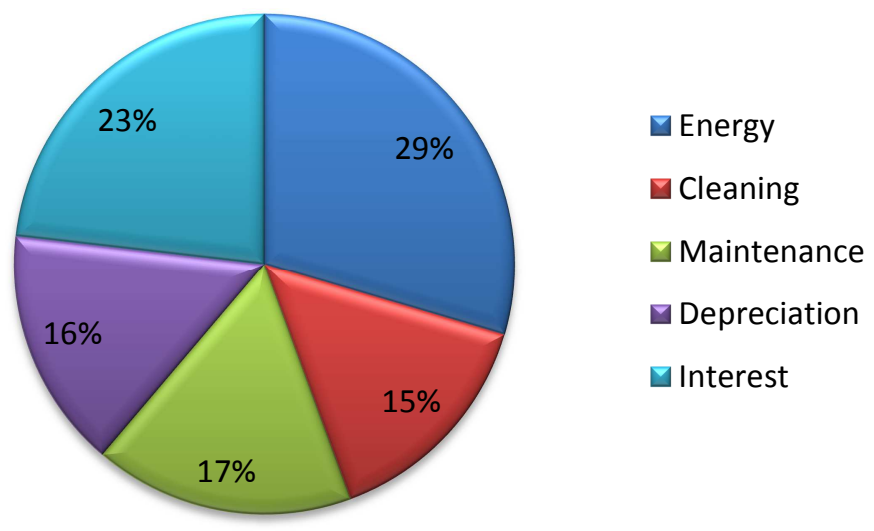

Graph 7 division of LCC in the standard scenario

\section{Conclusion}

Within the design process the focus should be directed to optimisation of initial costs as well as operating costs. This should be the emphasis of both the architect and other advisors, but especially those with a long term stake in the building.

With regard to the discussion on ratios the overestimating of the impact of operating costs $(1: 5: 200)$ with the publication of Evans (1998) is seen as a setback. By research of Hughes (2004) and Ive (2007) these ratios are diminished to a more recognisable bandwidth of 1:0,4-1,5:12-15, still depending on the applied discount rate and the considered building type. The results of our study fit well in this bandwidth, with a ratio of $1: 1,15-1,59$ for the initial costs versus the operating costs (discounted with $4 \%$ compared to $7 \%$ by Ive). This reduced ratio could be interpreted as operating costs are not that important which is not true. The possible gains will not be that impressive as it would be on the previous 1:5, but still the operating costs exceed the initial costs. Further improvement of buildings may in fact bring down the operating costs below the initial costs, reaching a better total result. In the end the ratio is only a tool to get the focus in the right direction, while the real target will be given by more absolute yearly costs figures. The cases are not dealing with the corporate operating costs, the last factor in the Evans' ratio. However, in the educational sector $79 \%$ off all costs are taken by staffing costs. In this perspective the contribution of the housing related costs are still modest, where cost cutting on building costs only will have a small positive impact on the overall feasibility, and may have a large negative impact on the staff performance. Steering on quality will only have negative financial consequences in some cases, but a large positive impact on life cycle cost and user appreciation.

Tools like GPR and BREEAM are dealing with a similar problem as observed in the ratios, lacking the dynamics of a holistic integral evaluation. On forehand a division in categories is made, e.g. energy versus other elements, where an element is rewarded a certain weight. Optimising or excelling on a certain element, however should have impact on the weight of that element in relation to the other elements. E.g. working on a zero energy building is increasing the impact of energy in the justification, where in some tools better performance leads to a lesser impact. In hindsight the cases are giving evidence the importance of the process at starting to use the building is underestimated; it took a while for some of the buildings to start performing as suggested by design, while in most cases the theoretical performance (EPC) is not reached at all.

The common fallacy that more sustainable buildings are more expensive is proven wrong again. In our cases the lesser expensive buildings are even performing slightly better on GPR-performance. At the same time the number of cases is not convincing enough for giving final evidence against this fallacy. Also the study is conducted with lifetimes of 40 years. It will be essential to research this aspect more into depth, with more realistic lifetimes up to 80 years, taking all the accompanying effects into account. 


\section{References}

De Jong, P. (2011). Investeren in een veranderlijke markt. In S. van Dam, S. Komossa \& L. Spoormans (Eds.), De transformatie van het schoolgebouw. Uitgeverij Thoth.

De Jonge, T. (2005). Cost effectiveness of sustainable housing investments. (Doctoral), Delft University Press, Delft.

Evans, R., Haryott, R., Haste, N., \& Jones, A. (1998). The Long Term Costs of Owning and Using Buildings: The Royal Academy of Engineering.

Gerritse, C. (2007). Controlling Costs and Quality in the Early Phases of the Accommodation Process. Delft: VSSD.

Hughes, W., Ancell, D., Gruneberg, S., \& Hirst, L. (2004). Exposing the myth of the 1:5:200 ratio relating initial cost, maintenance and staffing costs of office buildings. Paper presented at the 20th Annual ARCOM Conference,, Heriot Watt University.

In 't Veld, J., Hamdan, Y., \& Barendregt, E. (2010). Een fris alternatief voor de huisvesting van kinderen: PO Raad.

Ive, G. (2007). Re-examining the costs and value ratios of owning and occupying buildings. Building Research \& Information.

McDonough, W., \& Braungart, M. (2002). Cradle to cradle remaking the way we make things. New York: North Point Press.

Morris, P., \& Matthiessen, L. F. (2007). Cost of Green Revisited: Davis Langdon.

NEN-ISO. (2008). Buildings and constructed assets - Service-life planning - Part 5: Life-cycle costing (ISO 15686-5:2008,IDT).

Remøy, H., de Jong, P., \& Schenk, W. (2011). Adaptable office buildings. Property Management, 29(5), 11.

Van den Dobbelsteen, A. (2008). Towards closed cycles - New strategy steps inspired by the Cradle to Cradle approach. Paper presented at the PLEA 2008, Dublin.

Van der Pol, L. (2009). Gezond en goed, scholenbouw in topconditie. Den Haag.

Van Doorn, A., \& De Jong, P. (2012). Kosten en baten van een duurzaam project. In A. van Doorn \& E. van Bueren (Eds.), Het duurzame ontwerp project (pp. 195 ). Amsterdam: SUN.

Van Langen, J. (2012). Hoe presteren schoolgebouwen op levensduurkosten? (MSc), Delft University of Technology, Delft. Retrieved from http://repository.tudelft.nl/view/ir/uuid\%3A18f81cef711e-4d9a-9501-6041d53bd3d2/

\section{About the authors}

Peter de Jong is a lecturer Building Economics at the department Real Estate \& Housing of the Faculty of Architecture and The Built Environment at the Delft University of Technology since 2000. His teaching assignment is cost awareness in the design process (BSc Architecture) and feasibility studies. Research is moving towards life cycle costs, including supporting data classification and collection. Peter has taken part in classification of cost standards and the Dutch element method. With a history in building informatics, building information modelling has been a connecting thread in his career. The academic goal is to (re)define sustainable building economics with a strong focus on building quality.

Monique Arkesteijn is an assistant professor Real Estate Management and Development and head of the section Real Estate Management at the department of Real Estate and Housing of the Faculty of Architecture and The Built Environment at the Delft University of Technology. Monique is specialised in corporate real estate management and in the alignment of organisations and their real estate portfolio. 